\title{
Влияние ультрафиолетового излучения и электрического поля на проводимость структур на основе $\alpha-$ и $\varepsilon-\mathrm{Ga}_{2} \mathrm{O}_{3}$
}

\author{
(C) В.М. Калыгина ${ }^{1}$, В.И. Николаев ${ }^{2,3}$, А.В. Алмаев ${ }^{1}$, А.В. Цымбалов ${ }^{1}$, В.В. Копьев ${ }^{1}$, \\ Ю.С. Петрова ${ }^{1}$, И.А. Печников ${ }^{3}$, П.Н. Бутенко ${ }^{3}$ \\ ${ }^{1}$ Национальный исследовательский Томский государственный университет, \\ 634050 Томск, Россия \\ ${ }^{2} \mathrm{OOO} \mathrm{„Совершенные} \mathrm{кристаллы“,}$ \\ 194064 Санкт-Петербург, Россия \\ ${ }^{3}$ Физико-технический институт им. А.Ф. Иофффе Российской академии наук, \\ 194021 Санкт-Петербург, Россия \\ E-mail: Kalygina@ngs.ru
}

Поступила в Редакцию 27 мая 2020 г.

В окончательной редакции 2 июня 2020 г.

Принята к публикации 2 июня 2020 г.

Рассмотрено влияние ультрафиолетового излучения и сильного электрического поля на проводимость структур на основе двух типов полиморфных пленок оксида галлия. Оба типа пленок $\mathrm{Ga}_{2} \mathrm{O}_{3}$ получены осаждением из газовой фазы методом хлоридной эпитаксии на гладкие и структурированные сапфировые подложки ориентации (0001). В одном и том же процессе на гладких подложках росли $\alpha-\mathrm{Ga}_{2} \mathrm{O}_{3}$ пленки, а на структурированных - пленки оксида галлия, с регулярными структурами, перпендикулярными к подложке, содержащими чередующиеся области $\alpha$ - и $\varepsilon$-фазы. Резистивные структуры на основе двухфазных пленок обнаруживают переход из состояния с низким сопротивлением в состояние с высоким сопротивлением при воздействии излучения с $\lambda=254$ нм и сильного электрического поля. Время формирования отклика на УФ излучение $-5 \mathrm{c}$, время восстановления меньше $1 \mathrm{c}$.

Ключевые слова: оксид галлия, HVPE, полиморфизм, ультрафиолет, вольт-амперные характеристики.

DOI: $10.21883 /$ FTP.2020.10.49940.9449

\section{1. Введение}

Оксид галлия $\left(\mathrm{Ga}_{2} \mathrm{O}_{3}\right)$ является бинарным полупроводниковым соединением, которое может кристаллизоваться в пяти модификациях: $\alpha-, \beta-, \gamma-, \delta$ - и $\varepsilon[1-3]$. Благодаря своим физико-химическим свойствам этот широкозонный полупроводник представляет практический интерес для создания солнечно-слепых детекторов УФ диапазона, высоковольтных приборов, газовых сенсоров, беспроводной коммуникации и т. д. [4]. На сегодняшний день наиболее изученным является $\beta-\mathrm{Ga}_{2} \mathrm{O}_{3}$, имеющий ширину запрещенной зоны $E_{g} \sim 4.8$ эВ, что объясняется его высокой термической и химической стабильностью [5-7]. $\beta$-политип оксида галлия имеет моноклинную решетку, кристаллографические характеристики которой отличны от большинства традиционных полупроводниковых подложек, таких как: сапфир, кремний, карбид кремния и др. Это осложняет выращивание (в том числе эпитаксиальными методами) высококачественных слоев $\beta$ - $\mathrm{Ga}_{2} \mathrm{O}_{3}$ [8]. Политип $\alpha-\mathrm{Ga}_{2} \mathrm{O}_{3}$ имеет структуру корунда и небольшую разницу в постоянных кристаллической решетки с сапфиром: $3.3 \%$ (c) и 4.5\% (a) [9]. При этом $\alpha-\mathrm{Ga}_{2} \mathrm{O}_{3}$ обладает одной из самых больших шириной запрещенной зоны: $E_{g}=(5.1-5.3)$ эВ [10], что позволяет рассматривать его в качестве перспективного материала для создания солнечно-слепых детекторов в диапазоне глубокого УФ. В данной работе рассмотрено влияние структуры сапфировой подложки на электрические и фотоэлектрические характеристики слоев $\alpha$ - и $\varepsilon$-фаз оксида галлия.

\section{2. Методика эксперимента}

Эпитаксиаьные пленки оксида галлия $n$-типа проводимости, легированные оловом, выращены методом хлоридной газофазной эпитаксии (HVPE) ООО „Совершенные кристаллы“. Для осаждения использовали гладкие и структурированные сапфировые подложки (ССП) толщиной 380-430 мкм с ориентацией (0001). На гладких подложках были получены высококачественные однофазные $\alpha-\mathrm{Ga}_{2} \mathrm{O}_{3}$ слои, а на профилированных перпендикулярные подложке колончатые двухфазные структуры $\alpha-\mathrm{Ga}_{2} \mathrm{O}_{3} / \mathcal{\varepsilon}-\mathrm{Ga}_{2} \mathrm{O}_{3}$ ( далее $\alpha--\mid \varepsilon--\mathrm{Ga}_{2} \mathrm{O}_{3}$ ). На рис. 1 приведены данные растровой электронной микроскопии (РЭМ) для двухфазной пленки оксида галлия.

Подробно процесс получения и структура слоев были описаны ранее в работах $[11,12]$.

Для измерения электрических характеристик на поверхности слоев оксида галлия магнетронным напылением через шаблон были сформированы платиновые контакты. Расстояние между электродами составляло 1.85 мм. После этой операции сапфировые пластины с пленками оксида галлия при помощи скрайбирования разрезали на отдельные образцы размером $1.85 \times 1$ мм. Затем, используя золотую проволоку диаметром 50 мкм, 


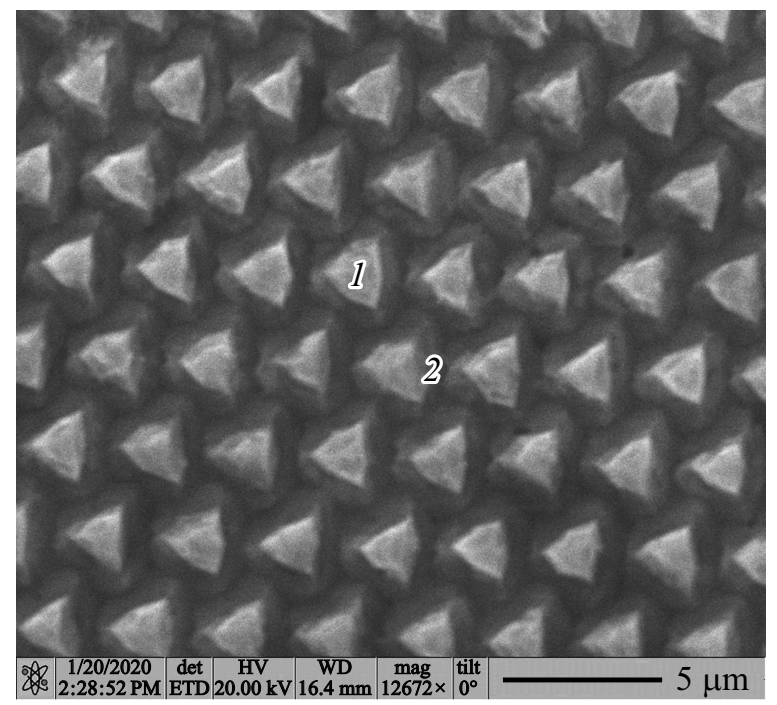

Рис. 1. РЭМ-изображение поверхности двухфазного слоя оксида галлия на структурированной сапфировой подложке, цифрами отмечены характерные области с различной кристаллографической структурой $1-\alpha-\mathrm{Ga}_{2} \mathrm{O}_{3}, 2-\varepsilon-\mathrm{Ga}_{2} \mathrm{O}_{3}$.

полученные образцы распаивали в стандартный корпус ТО-8.

Темновые вольт-амперные характеристики (BAX) и фотоэлектрические характеристики измеряли при комнатной температуре с помощью источника-измерителя Keithley 2611. В качестве источника ультрафиолетового (УФ) излучения использовали лампу VL-6 с фильтром, обеспечивающие генерацию длины волны $\lambda=254 \mathrm{Hм}$ (интенсивность излучения 3 мкВт/см ${ }^{2}$ ), и эксимерную $\mathrm{KrCl}$ лампу с $\lambda=222 \mathrm{нм}$, работающую в импульсном режиме.

\section{3. Экспериментальные результаты и их обсуждение}

В структурах, сформированных на гладких сапфировых подложках, обнаружены низкие темновые токи $\left(I_{D}\right)$, симметричные относительно полярности напряжения. В интервале $-200 \leq U \leq+200 \mathrm{~B}$ значения $I_{D}$ не превышают $1-6 \cdot 10^{-11} \mathrm{~A}$ (рис. 2).

Анализ вольт-амперных характеристик образцов показал: как темновые, так и фототоки при освещении УФ $\left(I_{L}\right)$ описываются линейной зависимостью $\ln (I) \sim U^{0.5}$ (рис. 3).

Такое поведение ВАХ соответствует инжекции электронов из металла в диэлектрик и описывается выражением (1) [13]:

$$
I=A^{*} T^{2} \exp \left(\frac{-e \Phi_{b}}{k T}\right) \exp \left(\frac{e \sqrt{e E / 4 \pi \varepsilon \varepsilon_{0}}}{k T}\right),
$$

где $A^{*}$ - постоянная Ричардсона для $\alpha-\mathrm{Ga}_{2} \mathrm{O}_{3}, T-$ абсолютная температура, $e-$ заряд электрона, $k-$ постоянная Больцмана, $\Phi_{b}$ - высота потенциального барьера на границе металл-оксид галлия, $E-$ напряженность электрического поля в диэлектрике, $\varepsilon_{0}$ - электрическая постоянная, $\varepsilon$ - диэлектрическая постоянная $\alpha-\mathrm{Ga}_{2} \mathrm{O}_{3}$.

Одной из причин отсутствия отклика образцов, выращенных на гладкой сапфировой подложке, на излучение с $\lambda=254 \mathrm{нм}(h v=4.88$ эВ) может быть их оптическая прозрачность при этой длине волны. Край поглощения $\alpha-\mathrm{Ga}_{2} \mathrm{O}_{3}$ находится при $\lambda \sim 235-240$ нм. Однако и при использовании источника с $\lambda=222 \mathrm{Hм} \quad(h v=5.6$ эВ $)$ отклик структур со слоем $\alpha-\mathrm{Ga}_{2} \mathrm{O}_{3}$ оказывается небольшим (см. рис. 2).

BAX двухфазных структур $\alpha-\mid \varepsilon-\mathrm{Ga}_{2} \mathrm{O}_{3}$, полученных на профилированных подложках, практически симметричны относительно полярности напряжения (рис. 4).

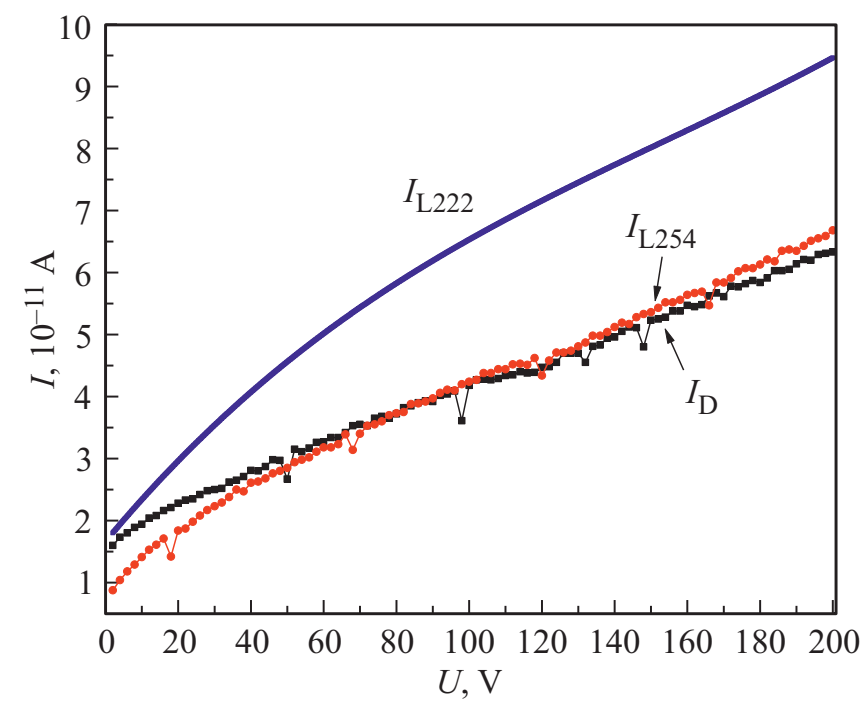

Рис. 2. ВАХ образца с пленкой $\alpha-\mathrm{Ga}_{2} \mathrm{O}_{3}: \mathrm{Sn}$, выращенной на гладкой сапфировой подложке: темновой ток $\left(I_{D}\right)$; токи $\left(I_{L}\right)$ во время действия УФ-излучения с $\lambda=254$ и 222 нм.

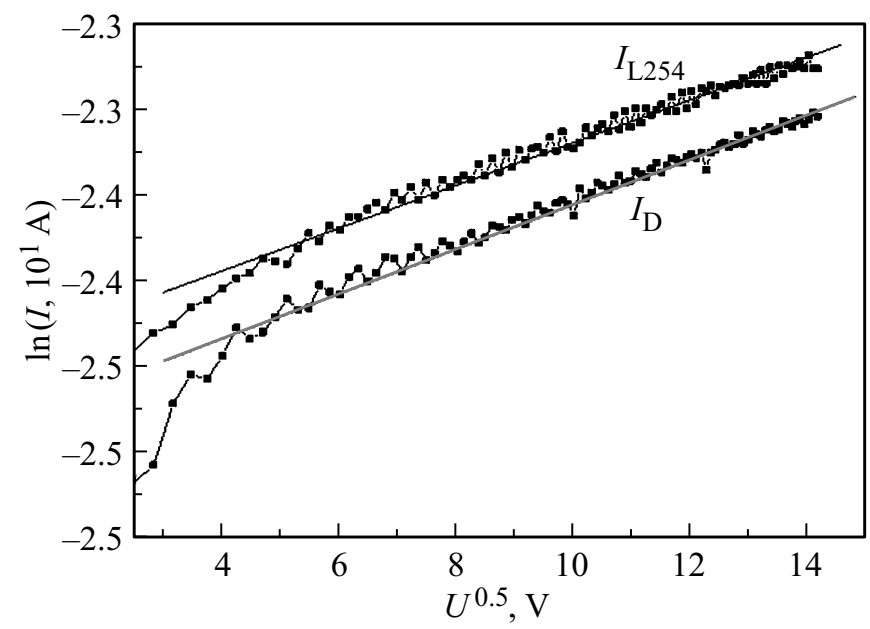

Рис. 3. ВАХ образца с пленкой $\alpha-\mathrm{Ga}_{2} \mathrm{O}_{3}: \mathrm{Sn}$ в координатах $\ln (I)-U^{0.5}: 1-$ темновой ток, 2 - ток во время УФ-облучения с максимумом при длине волны $\lambda=254$ нм. 


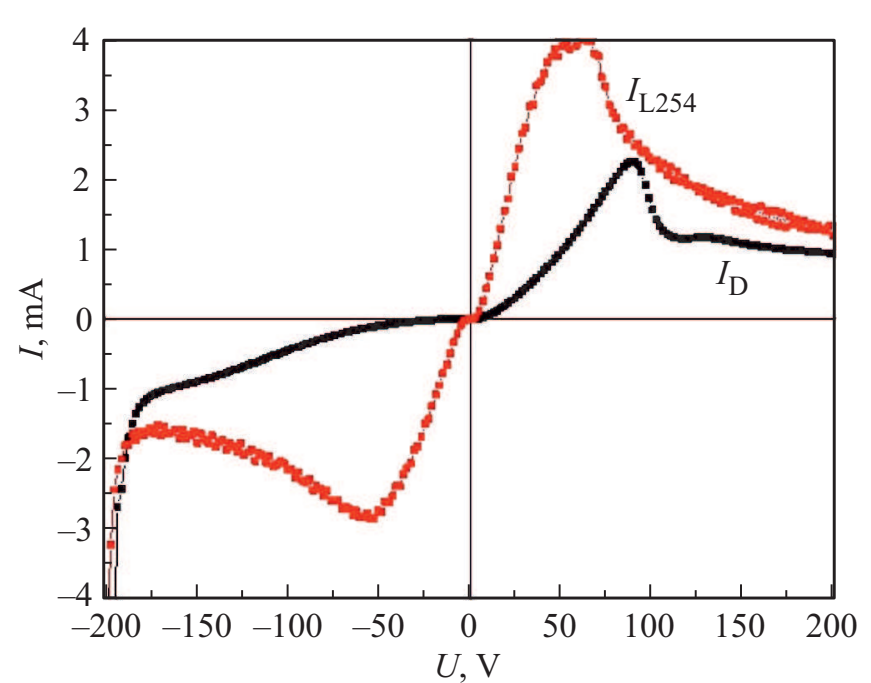

Рис. 4. ВАХ образца с пленкой оксида галлия на профилированной подложке в интервале $-200 \leq U \leq+200$ В.

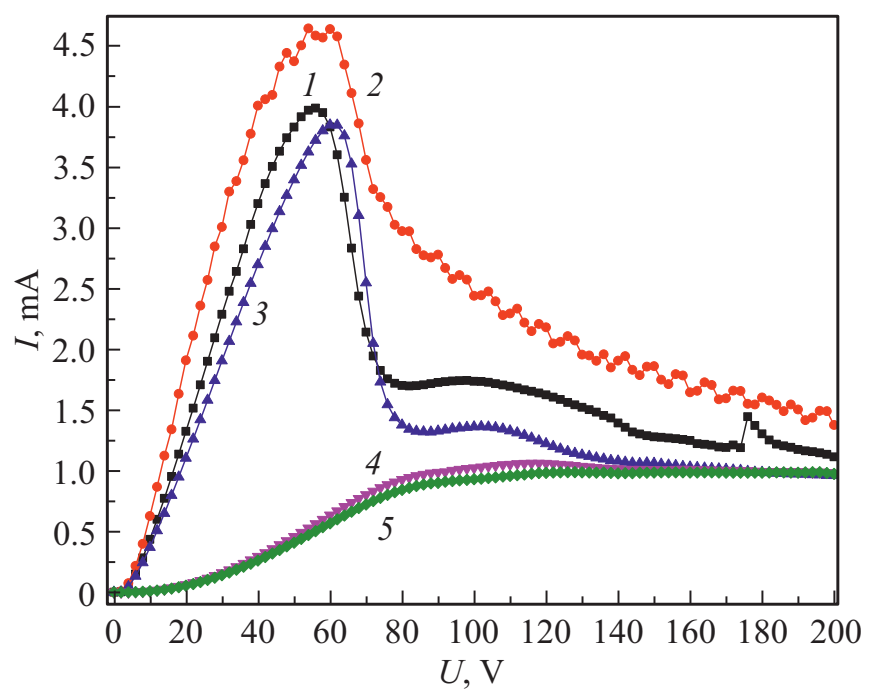

Рис. 5. ВАХ образца металл/ $\alpha-\mid \varepsilon-\mathrm{Ga}_{2} \mathrm{O}_{3} /$ металл на профилированной подложке: 1 - исходная темновая, $2-$ при действии УФ, 3 - темновая после УФ, 4, 5 - темновые после действия сильного электрического поля.

На рис. 5 показаны темновые ВАХ и при воздействии излучения с $\lambda=254$ нм при изменении напряжения в диапазоне $0 \leq U \leq 200 \mathrm{~B}$.

При подаче напряжения на образец исходные темновые токи (до воздействия сильных электрических полей и УФ излучения) увеличиваются с повышением напряжения по нелинейному закону и достигают максимальных значений при $U_{m}=50-70 \mathrm{~B}$ (в зависимости от образца). При $U>U_{m}$ темновой ток резко снижается, и при напряжениях $>80-100$ В менее сильно зависит от напряжения (рис. 5, кривая 1). В итоге темновая $\mathrm{BAX}$ изображается кривой с максимумом. Для четырех измеренных образцов максимальные значения темновых токов $I_{D}$ наблюдались при напряжениях $50-60 \mathrm{~B}$.
Зависимость тока от напряжения при воздействии излучения с $\lambda=254$ нм $\left(I_{L}\right)$ также изображается кривой с максимумом примерно при тех же напряжениях, что и максимальное значение темнового тока (рис. 5, кривая 2). При этом $I_{L}$ не на много превосходит значения темнового тока ID при фиксированных напряжениях на образце. Сразу после выключения УФ излучения образцы сохраняют повышенную проводимость (рис. 5, кривая 3), которая постепенно снижается. Если не подавать на образец напряжения, превышающие $100-120$ В, то повышенные значения темнового тока сохраняются в течение некоторого времени. Однако если на образец подать напряжение примерно равное 200 В, то характер темновой вольт-амперной характеристики резко изменяется: на кривой зависимости $I$ от $U$ исчезает максимум, и темновой ток при низких напряжениях на образце резко снижается (рис. 5, кривые 4,5). В этом случае темновая ВАХ определяется токами, ограниченными пространственным зарядом (ТОПЗ) при экспоненциальном распределении ловушек по энергии в запрещенной зоне диэлектрика и описывается выражением (2) [14]

$$
J=N_{c} \mu e^{1-l}\left[\frac{\varepsilon \varepsilon_{0} l}{N_{t}(l+1)}\right]^{l}\left(\frac{2 l+1}{l+1}\right)^{l+1} \frac{U^{l+1}}{L^{2 l+1}}
$$

где $N_{c}$ - эффективная плотность квантовых состояний в зоне проводимости оксида галлия, $\mu-$ подвижность электронов, $N_{t}-$ концентрация ловушек в пленке $\mathrm{Ga}_{2} \mathrm{O}_{3}, l=T / T_{c}, T_{c}$ - характеристическая температура, определяющая распределение ловушек по энергии в запрещенной зоне диэлектрика. На рис. 6 экспериментальная ВАX (кривая 5 на рис. 5) представлена в двойном логарифмическом масштабе в соответствии с формулой (2).

При напряжениях на образце до $10 \mathrm{~B}$ зависимость имеет вид $I \sim U^{2.0}$; в интервале $10 \leq U \leq 100 \mathrm{~B}$ зависимость имеет вид $I \sim U^{3.3}$; наконец, в диапазоне $100 \leq U \leq 200$ В зависимость имеет вид $I \sim U^{1.5}$. При повторной подаче напряжений в интервале

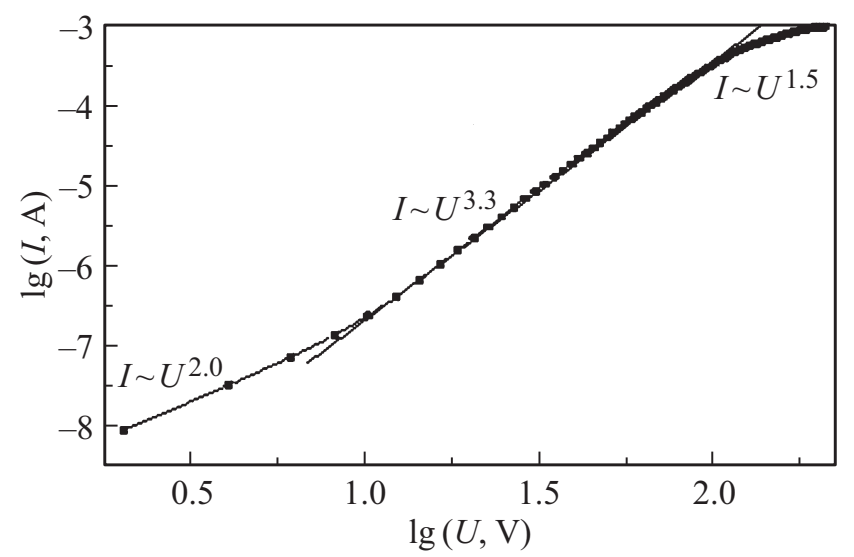

Рис. 6. ВАХ темнового тока структуры металл/ $\alpha-\mid \varepsilon-\mathrm{Ga}_{2} \mathrm{O}_{3} /$ металл в двойном логарифмическом масштабе образца после подачи напряжения 200 B. 


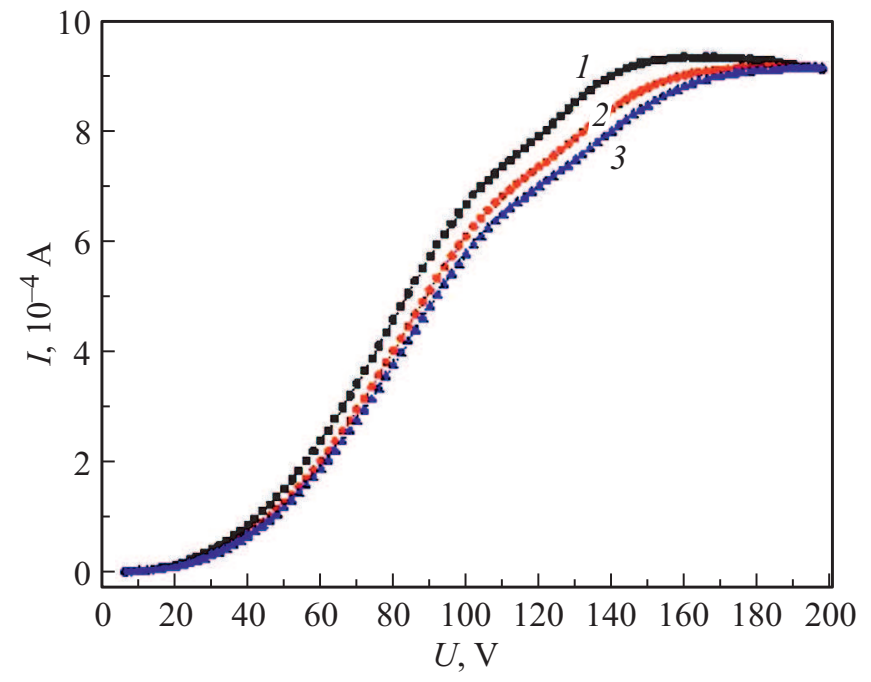

Рис. 7. Снижение темнового тока в структуре металл/ $\alpha-\mid \mathcal{\varepsilon}-\mathrm{Ga}_{2} \mathrm{O}_{3} /$ металл после подачи напряжения $200 \mathrm{~B}$; цифры около кривых соответствуют последовательности повышения напряжения от 0 до $200 \mathrm{~B}$.

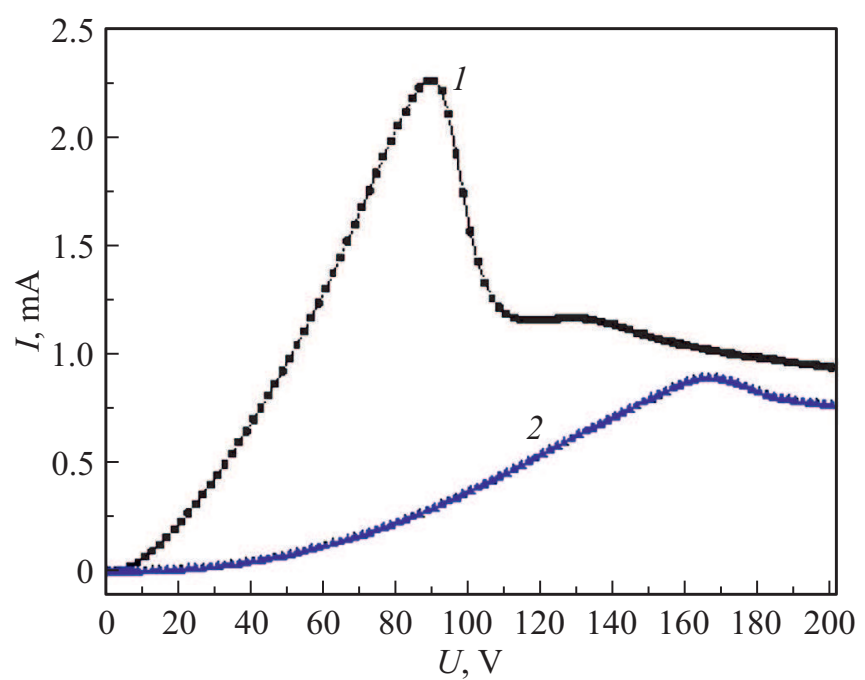

Рис. 8. Влияние электрического поля на темновые токи структуры металл/ $\alpha-\mid \varepsilon-\mathrm{Ga}_{2} \mathrm{O}_{3} /$ металл: до (1) и после (2) воздействия сильного электрического поля.

$0 \leq U \leq 200$ В темновой ток продолжает постепенно снижаться (рис. 7) и затем стабилизируется.

Таким образом, подавая высокие напряжения на структуры металл/ $\alpha-\mid \varepsilon-\mathrm{Ga}_{2} \mathrm{O}_{3} /$ металл, можно изменить механизм электропроводности образцов и существенно снизить исходные темновые токи. В результате кривые зависимости темнового тока от напряжения имеют вид, показанный на рис. 8.

Анализируя темновые BAX таких образцов, можно считать, что структуры обнаруживают эффект переключения из состояния с низким сопротивлением (НС) (рис. 8, кривая 1) в состояние с высоким сопротивлением (ВС) (рис. 8, кривая 2). Следует отметить: заметная чувствительность структур металл/ $\alpha-\mid \varepsilon-\mathrm{Ga}_{2} \mathrm{O}_{3} /$ металл к
УФ излучению появляется только после их переключения в состояние ВС. На рис. 9 показаны темновая BAX после перехода образца в состояние с высоким сопротивлением и ВАХ во время действия излучения с $\lambda=254$ нм. Используя данные на рис. 8 и формулу (3) [15], можно рассчитать удельную обнаружительную способность $D^{*}$ при максимальном значении фототока, которое соответствует напряжению $U=66 \mathrm{~B}$ :

$$
D^{*}=R\left(S_{k} /\left(2 e I_{D}\right)\right)^{1 / 2},
$$

где $R=I_{f} /\left(P S_{k}\right)$ - отклик детектора, $I_{f}=\left(I_{L}-I_{D}\right)-$ фототок, $S_{k}$ - площадь образца, $P-$ мощность излучателя на единицу площади. При расчете использовали следующие параметры: $I_{f}=4.28 \cdot 10^{-3} \mathrm{~A}, I_{D}=$ $=9.15 \cdot 10^{-5} \mathrm{~A}, S_{k}=1.85 \cdot 10^{-2} \mathrm{~cm}^{2}, P=2.8 \cdot 10^{-3} \mathrm{BT} / \mathrm{cm}^{2}$. Согласно расчету $D^{*}=2.1 \cdot 10^{10} \Gamma_{\amalg^{1 / 2}} \mathrm{~cm} / \mathrm{BT}$.

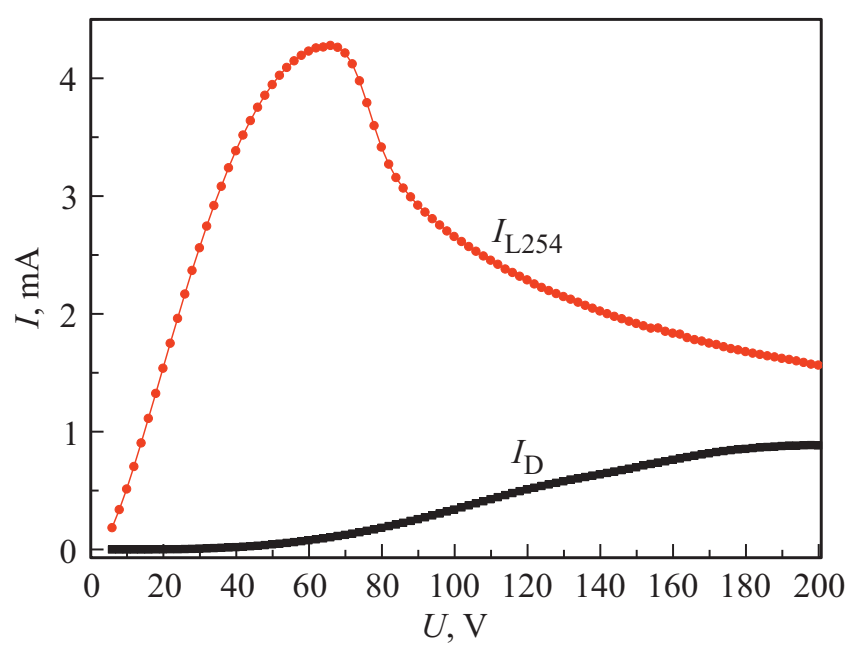

Рис. 9. Темновая ВАХ структуры металл/ $\alpha-\mid \varepsilon-\mathrm{Ga}_{2} \mathrm{O}_{3} /$ металл после подачи $200 \mathrm{~B}\left(I_{D}\right)$ и при действии излучении с $\lambda=254 \mathrm{HM}\left(I_{L}\right)$.

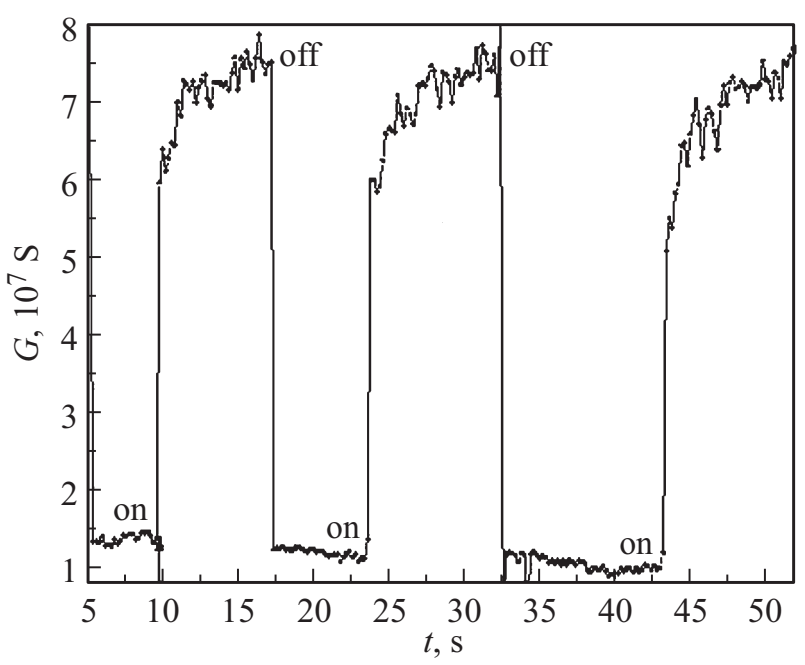

Рис. 10. Временна́я зависимость изменения проводимости структуры металл/ $\alpha-\mid \mathcal{\varepsilon}-\mathrm{Ga}_{2} \mathrm{O}_{3}$ Металл при включении и выключении источника излучения с $\lambda=254 \mathrm{HM}$, при $U=50 \mathrm{~B}$. 
На рис. 10 показана временна́я зависимость изменения проводимости образца $(G)$ при включении и выключении УФ излучения.

Оценка времени формирования отклика $\left(\tau_{r}\right)$ по уровню 0.9 показала, что оно не превышает $5 \mathrm{c}$, а время восстановления $\tau_{f} \leq 1 \mathrm{c}$.

Особенности полученных вольт-амперных характеристик образцов на профилированных подложках объясняются сложной структурой выращенных слоев оксида галлия. Пленки представляют собой последовательное чередование $\alpha$ - и $\varepsilon$-фаз $\mathrm{Ga}_{2} \mathrm{O}_{3}$ с разным типом кристаллических решеток и различной шириной запрещенных зон.

Предполагается, что большие значения темновых токов в образцах металл/ $\alpha-/ \varepsilon-\mathrm{Ga}_{2} \mathrm{O}_{3} / \alpha-\mathrm{Ga}_{2} \mathrm{O}_{3} / \ldots /$ $\alpha$ - $\varepsilon$ - $\mathrm{Ga}_{2} \mathrm{O}_{3} / \alpha$ - $\mathrm{Ga}_{2} \mathrm{O}_{3}$ /металл объясняются присутствием двумерного электронного газа (2DEG) в $\varepsilon$-фазе $\mathrm{Ga}_{2} \mathrm{O}_{3}$ за счет существования спонтанной поляризации $P_{s p}[16]$. Вектор спонтанной поляризации в $\mathcal{\varepsilon}-\mathrm{Ga}_{2} \mathrm{O}_{3}$ по направлению совпадает с постоянной кристаллической решетки „, ${ }^{\text {“ }}$ и под действием сильного электрического поля может изменять направление на противоположное. В результате нарушаются условия формирования 2DEG, и темновой ток при $U>U_{m}$ резко снижается.

В свою очередь исходное НС состояние объясняет слабую чувствительность структур металл/ $\alpha-\mid \varepsilon-\mathrm{Ga}_{2} \mathrm{O}_{3} /$ металл к УФ-излучению. Из сопоставления чувствительности к УФ-излучению образцов на гладкой подложке и ССП можно сделать вывод, что отклик на излучение с $\lambda=254$ нм обусловлен взаимодействием излучения с $\varepsilon$-фазой $\mathrm{Ga}_{2} \mathrm{O}_{3}$, имеющей меньшую ширину запрещенной зоны, для которой выполняется условие $h v \geq 4.6$ эВ.

Повышенные значения темновых токов после выключения УФ-излучения, вероятно, объясняются захватом носителей заряда на ловушечных центрах в $\varepsilon-\mathrm{Ga}_{2} \mathrm{O}_{3}$ [14]. После действия электрического поля система металл/ $\alpha-\mid \varepsilon-\mathrm{Ga}_{2} \mathrm{O}_{3}$ /металл медленно релаксирует в состояние с высоким сопротивлением. Наличие ловушечных центров в запрещенной зоне $\varepsilon-\mathrm{Ga}_{2} \mathrm{O}_{3}$ делает вполне реальным выше предложенный механизм протекания темновых токов (ТОПЗ) в исследованных структурах после тренировки их в сильных электрических полях.

\section{4. Заключение}

Исследованы электрические и фотоэлектрические характеристики структур резистивного типа металлполупроводник-металл на основе полиморфных пленок оксида галлия двух типов: однофазных $\alpha-\mathrm{Ga}_{2} \mathrm{O}_{3}$, и двухфазных $\alpha-\mid \varepsilon-\mathrm{Ga}_{2} \mathrm{O}_{3}$.

Полученные результаты позволяют сделать следующие выводы.

1. Электропроводность однофазных пленок $\alpha-\mathrm{Ga}_{2} \mathrm{O}_{3}: \mathrm{Sn}$, выращенных на гладких сапфировых подложках, не чувствительна к УФ излучению с $\lambda=254$ нм и слабо реагирует на излучение с $\lambda=222$ нм.

2. Структуры на основе двухфазных пленок $\alpha-\mid \varepsilon-\mathrm{Ga}_{2} \mathrm{O}_{3}$, выращенных на структурированных подложках, обнаруживают эффект переключения в сильных электрических полях из состояния с низким сопротивлением в состояние с высоким сопротивлением. В состоянии с низким сопротивлением вольт-амперные характеристики изображаются кривыми максимумом при напряжениях 50-70 В.

3. Структуры с пленками $\alpha-\mid \varepsilon-\mathrm{Ga}_{2} \mathrm{O}_{3}$ обнаруживают чувствительность к УФ излучению $(\lambda=254 \mathrm{Hм})$, но только после тренировки в сильных электрических полях. Удельная обнаружительная способность составляет $D^{*}=2.1 \cdot 10^{10} \Gamma_{ц^{1 / 2}} \mathrm{~cm} / \mathrm{BT}$.

4. Время формирования отклика на УФ излучение $(\lambda=254 \mathrm{нм})$ не превышает $4-5$ с, время восстановления $\leq 1 \mathrm{c}$.

5. Структуры обнаруживают „замороженную“ фотопроводимость, оторая „стирается“ с помощью сильного электрического поля.

\section{Конфликт интересов}

Авторы заявляют, что у них нет конфликта интересов.

\section{Список литературы}

[1] S. Lee, Y. Ito, K. Kaneko, S. Fujita. Jpn. J. Appl. Phys., 54, 3 (2015).

[2] A.A. Dakhel. Sol. St. Sci., 20, 54 (2013).

[3] S.I. Stepanov, V.I. Nikolaev, V.E. Bougrov, A.E. Romanov. Rev. Adv. Mater. Sci., 44, 63 (2016).

[4] I. Cora, F. Mezzadri, F. Boschi, M. Bosi, M. Caplovicova, G. Calestani, I. Dodony, B. Pecza, R. Fornari. Cryst. Eng. Commun., 19, 1509 (2017).

[5] D. Guo, X. Qin, M. Lv, H. Shi, Y. Su, G. Yao, S. Wang, C. Li, P. Li, W. Tang. Electron. Mater. Lett., 13, 483 (2017).

[6] L. Qian, Z. Wu, Y. Zhang, P. Lai, X. Liu, Y. Li. ACS Photonics, 4, 2203 (2017).

[7] J.W. Roberts, P.R. Chalker, B. Ding, R.A. Oliver, J.T. Gibbon, L.A.H. Jones, V.R. Dhanak, L.J. Phillips, L.J. Major, F.C. Massabuau. J. Cryst. Growth, 528, 125254 (2019).

[8] X. Xia, Y. Chen, Q. Feng, H. Liang, P. Tao, M. Xu, G. Du. Appl. Phys. Lett., 108, 202103 (2016).

[9] H. Son, Y. Choi, J. Hwang, D. Jeon, Y. Ra, Y. Lee, J. Kim, S. Kim, T. Lim. ECS J. Solid State Sci. Technol., 8, 3024 (2019).

[10] Y. Xu, C. Zhang, Y. Cheng, Z. Li, Y. Cheng, Q. Feng, D. Chen, J. Zhang, Y. Hao. Materials, 12, 3670 (2019).

[11] V.I. Nikolaev, A.I. Pechnikov, V.V. Nikolaev, M.P. Scheglov, A.V. Chikiryaka, S.I. Stepanov, O.S. Medvedev, S.V. Shapenkov, E.V. Ubyivovk, O.F. Vyvenko. J. Phys.: Conf. Ser., 1400, 055049 (2019).

[12] S. Shapenkov, O. Vyvenko, E. Ubyivovk, O. Medvedev, G. Varygin, A. Chikiryaka, A. Pechnikov, M. Scheglov, S. Stepanov, V. Nikolaev. Phys. Status Solidi A, 217, 1900892 (2020). 
[13] C. Shih. Adv. Mater. Sci. Engin., 2014, 4 (2014).

[14] М. Ламперт, П. Марк. Инжекционные токи в твердых meлах (М., Мир, 1973).

[15] G.C. Hu, C.X. Shan, N. Zhang, M.M. Jiang, S.P. Wang, D.Z. Shen. Opt. Express, 23, 13559 (2015).

[16] S.B. Cho, R. Mishra. Appl. Phys. Lett., 112, 162101 (2018).

Редактор Г.А. Оганесян

\section{The influence of ultraviolet radiation and electric field on the conductivity of structures based on $\alpha$ - and $\varepsilon-\mathrm{Ga}_{2} \mathrm{O}_{3}$}

V.M. Kalygina', V.I. Nikolaev',3, A.V. Almaev', A.V. Tsymbalov' ${ }^{1}$, V.V. Kopyev ${ }^{1}$, Y.S. Petrova ${ }^{1}$, I.A. Pechnikov ${ }^{3}$, P.N. Butenko ${ }^{3}$

${ }^{1}$ National Research Tomsk State University, 634050 Tomsk, Russia

2 „Perfect Crystals“ LLC, 194064 St. Petersburg, Russia

3 loffe Institute,

194021 St. Petersburg, Russia

Abstract The influence of ultraviolet radiation and a strong electric field on the current-voltage characteristic of resistive structures based on polymorphic films of gallium oxide is studied. Both types of $\mathrm{Ga}_{2} \mathrm{O}_{3}$ films were obtained by the method of chloride vapor-phase epitaxy on smooth and structured sapphire substrates with orientation (0001). In the same process $\alpha-\mathrm{Ga}_{2} \mathrm{O}_{3}$ films were deposited on smooth substrates, and gallium oxide films, with regular structures perpendicular to the substrate, containing alternating regions of the $\alpha$ - and $\varepsilon$-phases were deposited on patterned substrate. It's was observed, that radiation with $\lambda=254 \mathrm{~nm}$ and strong electric transfer structures from a state with low resistance to a state with high resistance. The response time to $U_{V}$ radiation is $5 \mathrm{~s}$, and the recovery time less than $1 \mathrm{~s}$. 